\title{
Comparative effects of Silymarin and zinc complex of Betulinic acid on pyrazinamide induced Histopathological changes in Mice liver
}

\author{
ALIA REHMAN 1 , SALMA SALIM², ZUNAIRA QAYYUM ${ }^{3}$, NIMRA IJAZ ${ }^{4}$ \\ ${ }^{1}$ Demonstrator (MBBS), Department of Pharmacology Mohtarma Benazir Bhutto Shaheed Medical College Mirpur, AJK \\ ${ }^{2}$ Demonstrator (MBBS), Pharmacology Mohi-ud-din Islamic Medical College Mirpur, AJK \\ ${ }^{3}$ Demonstrator (MBBS, M.Phil Morbid Anatomy and Histopathology) Department of Pathology Mohtarma Benazir Bhutto Shaheed Medical \\ College Mirpur, AJK \\ ${ }^{4}$ Nimra ljaz (MBBS, M.Phil Pharmacology) Demonstrator Pharmacology, Fauji Foundation medical College Islamabad \\ Correspondence to: Dr Alia Rehman, Email: aliarehmanraja@yahoo.com, Cell: +92 03475493859
}

\begin{abstract}
Introduction: Liver is an important organ in the body. Due to its role in metabolism of drugs it is also a major site of drug induced liver injury. Oxidative stress plays an important role in DILI therefore use of nti-oxidants has been proposed to combat liver injury.

Objective of the Study: To measure and compare Hepatoprotective effects of Zinc complex of Betulinic acid and Silymarin due to their antioxidant effects on Pyrazinamide induced Hepatotoxicity in mice.

Methodology: It was an experimental randomized control trial. The research was conducted at the Department of Pharmacology and Therapeutics and Multidisciplinary research laboratory at IIMCT with mutual collaboration of National Institute of Health (NIH) in Islamabad, Pakistan. Research was started after the official approval of synopsis by accredited Ethical Review Committee. Study duration was one year from 1 September 2020 to 31 august 2021. 24 adult Balb-C mice were randomly divided into four groups. Group 1 was Negative Control (NC) and did not receive any intervention. Oral pyrazinamide $(500 \mathrm{mg} / \mathrm{kg})$ was administered for 28 days to the group 2 (disease control) alone and to group 3 and 4 in combination with Silymarin $(100 \mathrm{mg} / \mathrm{kg})$ and Zinc complex of Betulinic Acid $(1 \mathrm{mg} / \mathrm{kg})$ respectively. Mice were dissected after completion of experiment and liver samples were taken for Histopathological analysis. Hepatoprotective function of Silymarin and zinc complex of Betulinic acid was evaluated in group 3 and 4 by Histopathological changes.

Results: Significant $(\mathrm{p}<0.05)$ changes were seen in parameters (necrosis, inflammatory cell infiltration and vascular congestion) among groups.

Conclusion: This study proves protective effects of zinc complex of Betulinic acid and Silymarin on pyrazinamide induced hepatotoxicity.

Key Words: Hepatotoxicity, Betulinic Acid, Silymarin, Pyrazinamide, Zinc, Tuberculosis
\end{abstract}

\section{INTRODUCTION}

Liver is one of the vital organ in the body which performs a variety of important functions such as metabolism of lipids, proteins and carbohydrates, production of coagulation factors, metabolism of drugs, Xenobiotics and nutritional substances . ${ }^{1}$ Tuberculosis is a disease which is caused by an infectious agent Mycobacterium tuberculosis .It has hgh incidence in the countries which have low income rate that's why it is also known as disease of poverty .Pakistan is ranked at fifth position among first 22 high burden countries of tuberculosis. WHO report about TB incidence published in 2016 stated that incidence in Pakistan is 270 per 100,000 population ${ }^{2}$ According to an a study TB is responsible for causing 1.4 million deaths every year

${ }^{3}$ First line anti-TB drugs include Isoniazid, rifampicin , pyrazinamide and ethambutol ${ }^{4}$. Among the first line antiTB drugs first three are hepatotoxic and are known to cause drug induced liver injury. TB patients taking ATT medication has an incidence of about $2-28 \%$ of drug induced liver injury . ${ }^{5}$ Pyrazinamide has been documented to be more hepatotoxic in comparison with isoniazid and rifampicin.$^{6}$ mechanism of pyrazinamide induced hepatotoxicity involves oxidative stress caused by the changes brought about by pyrazinamide on the antioxidants .

Betulinic acid is a lupane-type triterpenoid with a pentacyclic structure which is naturally occuring .It has wide distribution in plant kingdom. Number of plants are source of BA such as Doliocarpus schottianus, Ancistrocladusheyneaus, Ziziphus spina-christi. ${ }^{8}$ Pharmacological activities associated with BA include antitumor activity, anti-oxidant activity, Hepatoprotective activity , cardio protective activity , anti-inflammatory activity as well as nephroprotective effects. ${ }^{9}$ Some of the useful effects in hepatic injury are associated with effects of this compound on anti-oxidants such as GSH , superoxide dismutase and the ability of BA to inhibit lipid peroxidation. ${ }^{10}$

Zinc is a commonly occuring trace element in the human body.${ }^{11}$ Antioxidant effects of zinc are attributed to increased production of metallothioneins, activation of catalases and glutathiones protection of protein sulfahydryls from oxidation as well as replacement of zinc with copper , iron and other redox active metals on binding sites. ${ }^{12}$ Hepatoprotective effect of zinc are due to its ability to inhibit hepatic lipid deposition along with its antioxidant and anti- inflammatory effects ${ }^{13}$

Silymarin is a combination of flavonolignans which are extracted from the milk thistle It is standard drug used in various liver ailments due to its anti-oxidant, antiinflammatory as well as anti-fibrotic properties along with its ability to inhibit free radicle generation. Therefore study is designed to observe Hepatoprotective effects of both the Zinc complex of Betulinic acid and Silymarin keeping in mind their anti-oxidant properties so that they can be used as adjunct drug therapy 


\section{MATERIALS AND METHODS}

It was an Experimental randomized control study. It was conducted at Pharmacology department, Islamic International Medical College (IIMC) in collaboration with Riphah Institute of Pharmaceutical Sciences (RIPS) and animal house of National Institute of Health (NIH), Islamabad from September 2020 to September 2021. Approval of research proposal was from Institutional Review Committee. 24 healthy male albino Balb/C mice with weight of approximately $30-50 \mathrm{~g}$ and life of 8 weeks and normal LFT, s was included in study. Mice which have weight less than $30 \mathrm{~g}$, age less than 8 weeks and female mice were not included in the study. Mice were kept under room temperature of $22 \pm 2$ degree Celsius and 12 hour light dull cycle for 1 week. The mice were randomly divided into four groups each containing 6 mice in each group $(n=6)$. Group 1, control group was given normal diet and tap water. Group 2, drug treated group was given pyrazinamide in dose of $500 \mathrm{mg} / \mathrm{kg}^{14}$ Group 3 was given Silymarin $100 \mathrm{mg} / \mathrm{kg}^{15}$ and group 4 was given zinc complex of Betulinic Acid ${ }^{10}$ in $1 \%$ starch jelly .

After completion of 28 days of duration of the trial, mice were anesthetized with chloroform and placed in flat posture with their limbs pinned on dissection table. Abdomen was opened with a longitude cut and liver was identified and exposed. It was detached from neighboring structures and was instantly put into containers having $10 \%$ formalin. Dehydration of the tissue is done by ethanol ascending grades. After dehydration liver tissue is cleared by xylene and then its embedding is done by paraffin wax. After that tissue blocks are made which measure 4-5 microns which are then used for histological analysis .Slides were stained by using Eosin and Hematoxylin stain. The slides were then used to analyse the following parameters : necrosis, imflammatory cells infiltration and vascular congestion which are the normal findings found in pyrazinamide induced hepatic injury.

Data Analysis: Respective data was entered and analyzed in SPSS version 21.Mean and standard errors were calculated for the quantitative variables. Categorical or qualitative variables were demonstrated by frequency and percentage. Chi square test was applied for comparison of histological qualitative variables.

\section{RESULTS}

Table 1: distribution of necrosis among all groups through ChiSquare test

\begin{tabular}{|l|l|l|l|}
\hline & Absent (\%) & Present (\%) & P-Value \\
\hline Group 1 & (6) $100 \%$ & $(0) 0 \%$ & \multirow{2}{*}{$0.001^{*}$} \\
\hline Group 2 & (0) $0 \%$ & (6) $100 \%$ & \\
\hline Group 3 & (4) $66 \%$ & $(2) 33 \%$ & \\
\hline Group 4 & (4) $66 \%$ & $(2) 33 \%$ & \\
* Significant & & &
\end{tabular}

Table 2: Chi -Square test showing inflammatory cells infiltration among all Group

\begin{tabular}{|l|l|l|l|}
\hline Group & Absent (\%) & Present (\%) & P-Value \\
\hline Group 1 & $(6) 100 \%$ & $(0) 0 \%$ & \multirow{2}{*}{$0.000^{*}$} \\
\hline Group 2 & $(0) 0 \%$ & $(6) 100 \%$ & \\
\hline Group 3 & $(4) 66 \%$ & $(2) 33 \%$ & \\
\hline Group 4 & $(6) 100 \%$ & $(0) 0 \%$ & \\
\hline * Significan & &
\end{tabular}

There was significant $(p<0.0 .5)$ difference in groups and necrosis. Necrosis was present in all mice of group 2, $33 \%$ in group 3 and $33 \%$ in group 4 .

Distribution of inflammatory cells infiltration showed that there was significant $(p<0.05)$ difference between groups and infiltration. Infiltration of inflammatory cells was present in all animals of group 2, 33\% in group 3, $0 \%$ in group 4.

Table 3. Chi-Square test showing distribution of vascular congestion among all groups

\begin{tabular}{|l|l|l|l|}
\hline Group & Absent (\%) & Present (\%) & P-Value \\
\hline Group 1 & $(6) 100 \%$ & $(0) 0 \%$ & \\
\cline { 1 - 3 } Group 2 & $(0) 0 \%$ & $(6) 100 \%$ & \multirow{2}{*}{$0.002^{*}$} \\
\hline Group 3 & $(4) 66 \%$ & $(2) 33 \%$ & \\
\hline Group 4 & $(5) 84 \%$ & $(1) 16 \%$ & \\
\hline
\end{tabular}

${ }^{*}=$ Significant

Distribution of vascular congestion shows significant difference $p<0.05$ among groups. Vascular congestion was absent in all animals of group 1 .It was present in all animals of group 2, $33 \%$ in group 3 and $16 \%$ in group 4 .

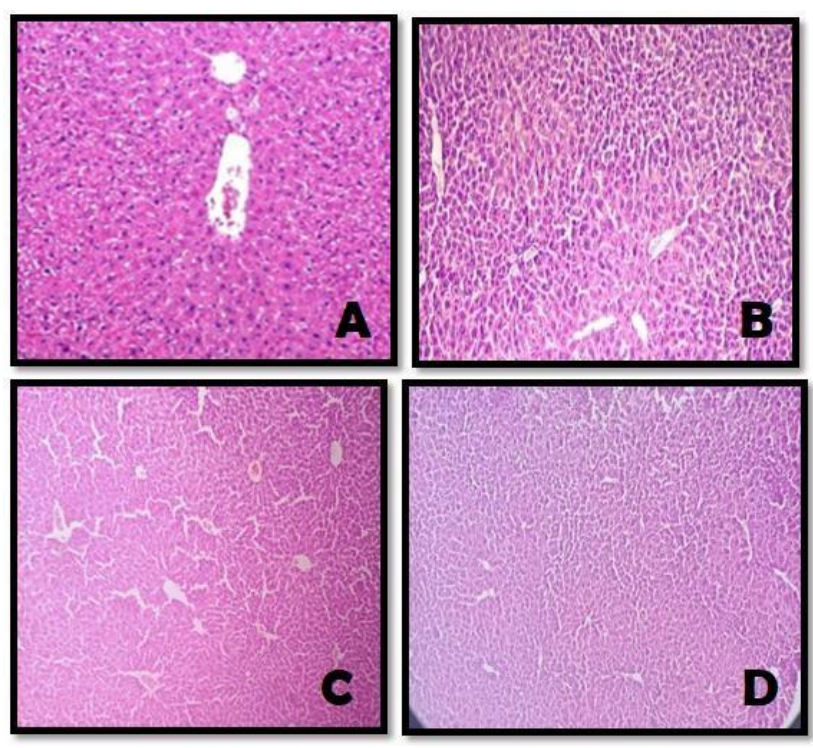

Figure 1 : Histopathological changes in mouse liver (10X) , Group A showing normal hepatic architecture, Group 2 showing necrosis inflammation and vascular congestion, group 3 and 4 showing preservation of normal hepatic architecture.

\section{DISCUSSION}

In the current study Pyrazinamide administration in disease control group caused significant necrosis and inflammatory cell infiltration. These findings were in accordance with the study carries out by V.Kovalenko et al. who used pyrazinamide to study epigenetic changes in rat liver. Use of $\mathrm{PZ}$ produced significant histological changes in rat liver .${ }^{16}$ These findings were also supported by S.Taziki et al. who used pyrazinamide to study the Hepatoprotective effects of taurine .In his study administration of PZ produced significant necrosis and inflammation in rats.$^{17}$

In our study there was also significant $(p<0.05)$ improvement in histological parameters including necrosis, vascular congestion and infiltration of inflammatory cells by 
the use of $\mathrm{Zn}$ and $\mathrm{BA}$ in experimental group 4 in comparison with the Disease Control Group .The beneficial effects of BA $n$ liver histology was in accordance with the findings of Abdullah et al. ${ }^{18}$ who proved antihepatotoxic activity of Betulinic acid due to its protective effect on antioxidant system and its membrane stabilizing activity. These findings were also in accordance with the study done by $A$. Ahangarpour ${ }^{19}$ who studied the effects of Betulinic Acid on hepatic enzyme levels and histology on streptozotocin -nicotinamide -induced diabetic rats and showed that Betulinic acid pretreatment effectively reduces hepatic necrosis and inflammation. Similar findings regarding zinc were reported by $W$. Siddique ${ }^{20}$ who studied the effect of zinc sulfate on ATT induced hepatotoxicity and showed that zinc protects against liver injury through its antioxidant effect. Findings in the present study were also supported by F.Al-Jawad et al. ${ }^{21}$

Both the biochemical and Histopathological effects of Silymarin in our study were supported by E.Sabina et al. ${ }^{22}$ and S.Tasduq et al. ${ }^{23}$ both of which observed Hepatoprotective effects of Silymarin in ATT induced liver damage. Both of these studies demonstrated that use of Silymarin against ATT induced hepatotoxicity results in preservation of normal hepatic architecture with no evidence of necrosis, steatosis and inflammation.

\section{CONCLUSION}

In the present study it is concluded that Silymarin and Zinc Complex of Betulinic Acid individually ameliorate the hepatotoxic effect induced by Pyrazinamide and can be used as adjuncts in the treatment DILI caused by oxidative stress.

\section{REFERENCES}

1. Wakim KG. Physiology of the liver. Am $J$ Med. 1954;16(2):256-71.

2. Abebe G, , Zegeye Bonsa WK. Treatment Outcomes and Associated Factors in Tuberculosis Patients at Jimma University Medical Center: A 5-Year Retrospective Study Gemeda. Int J Mycobacteriology. 2017;6(3):239-45.

3. Meiah Ngafidin KN, Suryono S, Isnanto RR. Diagnosis of Tuberculosis by Using a Fuzzy Logic Expert System. Proc 2019 4th Int Conf Informatics Comput ICIC 2019. 2019;

4. Chiang SS, Starke JR. Mycobacterium tuberculosis [Internet]. Fifth Edit. Principles and Practice of Pediatric Infectious Diseases. Elsevier Inc.; 2018. 790-806.e5 p. Available from: http://dx.doi.org/10.1016/B978-0-323-401814.00134-1

5. Marjani M, Fahimi F, Sadr M, Dizaji MK, Moniri A, Khabiri S, et al. Evaluation of Silymarin for management of antituberculosis drug induced liver injury: A randomized clinical trial. Gastroenterol Hepatol from Bed to Bench. 2019;12(2):138-42.

6. Jeong I, Song J, Yoon H II, Lee C-T, Lee J-H. Drug Induced Hepatotoxicity of Antituberculosis Drugs and Their Serum Levels. Chest. 2011;140(4):771A.

7. $\quad$ Stress O, Drug-induced FA. crossm. 2018;1-11.
8. Ríos JL, Máñez S. New Pharmacological Opportunities for Betulinic Acid. Planta Med. 2018;84(1):8-19.

9. Silva FSG, Oliveira PJ, Duarte MF. Oleanolic, Ursolic, and Betulinic Acids as Food Supplements or Pharmaceutical Agents for Type 2 Diabetes: Promise or Illusion? J Agric Food Chem. 2016;64(15):2991-3008.

10. Yi J, Xia W, Wu J, Yuan L, Wu J, Tu D, et al. Betulinic acid prevents alcohol-induced liver damage by improving the antioxidant system in mice. J Vet Sci. 2014;15(1):141-8.

11. Olechnowicz J, Tinkov A, Skalny A, Suliburska J. Zinc status is associated with inflammation, oxidative stress, lipid, and glucose metabolism. J Physiol Sci. 2018;68(1):19-31.

12. Marreiro D do N, Cruz KJC, Morais JBS, Beserra JB, Severo JS, Soares de Oliveira AR. Zinc and oxidative stress: Current mechanisms. Antioxidants. 2017;6(2).

13. Liu J, Zhou ZX, Zhang W, Bell MW, Waalkes MP. Changes in hepatic gene expression in response to hepatoprotective levels of zinc. Liver Int. 2009;29(8):1222-9.

14. Taziki S, Khori V, Jahanshahi M, Seifi A, Babakordi F, Nikmahzar E. Protective role of taurine against hepatotoxicity induced by pyrazinamide in rats. Natl $\mathrm{J}$ Physiol Pharm Pharmacol. 2018;8(6):1.

15. Bektur NE, Sahin E, Baycu C, Unver G. Protective effects of silymarin against acetaminophen-induced hepatotoxicity and nephrotoxicity in mice. Toxicol Ind Health. 2013;32(4):589600.

16. Kovalenko VM, Bagnyukova T V., Sergienko O V., Bondarenko LB, Shayakhmetova GM, Matvienko A V., et al. Epigenetic changes in the rat livers induced by pyrazinamide treatment. Toxicol Appl Pharmacol. 2007;225(3):293-9.

17. Taziki S, Khori V, Jahanshahi M, Seifi A, Babakordi F, Nikmahzar E. Protective role of taurine against hepatotoxicity induced by pyrazinamide in rats. Natl $\mathrm{J}$ Physiol Pharm Pharmacol. 2018;(July 2019):1.

18. Abdullah, Khan MA, Ahmad W, Adhikari A, Ibrar M, Rehman $M$ ur, et al. Exploration of hepatoprotective potential and phytochemicals of ziziphus oxyphylla edgew. Pak Vet J. 2020;40(4):431-6.

19. Ahangarpour A, Shabani R, Farbood $Y$. The effect of betulinic acid on leptin, adiponectin, hepatic enzyme levels and lipid profiles in streptozotocin-nicotinamide-induced diabetic mice. Res Pharm Sci. 2018;13(2):142-8.

20. Siddique W, Rashid N, Asim S, Firdous A, Siddique H, Hanif $A$, et al. Comparison of Histoprotective effect of Silymarin and Zinc Sulfate against Hepatotoxicity induced. Pakistan J Med Heal Sci. 2021;15(1):73-8.

21. Al-Jawad FH, Sharquie KE, Raghif AA, Nashtar SB. Hepatoprotective effects of zinc sulphate and silymarin against thallium-induced poisoning in rats. IRAQI Acad Sci Journals [Internet]. 2016;(March):42-57. Available from: https://www.iasj.net/iasj?func=article\&ald $=106832$

22. Sabina EP, Peter S J, Prathap S, Geetha A. A comparison of hepatoprotective activity of Bacoside to Silymarin treatment against a combined Isoniazid and Rifampin-induced hepatotoxicity in female Wistar rats. J Histotechnol [Internet]. 2019;42(3):128-36. Available from: https://doi.org/10.1080/01478885.2019.1638535

23. Tasduq SA, Peerzada K, Koul S, Bhat R, Johri RK. Biochemical manifestations of anti- tuberculosis drugs induced hepatotoxicity and the effect of silymarin. Hepatol Res. 2005;31(3):132-5. 